\title{
Sunlight-Driven Copper-Catalyst Activation Applied to Photolatent Click Chemistry
}

\author{
Rédouane Beniazza, ${ }^{[a]}$ Romain Lambert, ${ }^{[a]}$ Lydie Harmand, ${ }^{[a]}$ Florian Molton, ${ }^{[b]}$

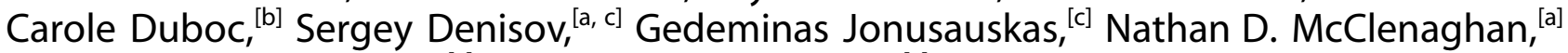 \\ Dominique Lastécouères, ${ }^{[a]}$ and Jean-Marc Vincent* ${ }^{[a]}$
}

Abstract: The synthesis, full characterization, photoreduction properties, and catalytic activity for the copper(I)-catalyzed alkyne-azide cycloaddition (CUAAC) reaction of a copper(II)DMEDA ( $N, N^{\prime}$-dimethylethylendiamine) complex is reported. Spectroscopic studies (UV/Vis, EPR) demonstrated that under daylight illumination highly effective copper(II) to copper(I) reduction occurs in this complex. These findings are in agreement with a high photoreduction quantum yield value of 0.22 in $\mathrm{MeOH}$, and a value approaching unity as determined in THF. The reduction process, which can also be conducted by irradiation at $365 \mathrm{~nm}$ by using a standard TLC (thin layer chromatography) lamp, is ascribed to a highly ef- ficient photoinduced electron transfer (PET) process mediated by the benzophenone photosensitizer present in the carboxylate counterion. Having deaerated the reaction mixture, the photogenerated copper(I) species proved to be highly active for the CUAAC reaction, demonstrated by reactions conducted with low catalyst loading $(0.5 \mathrm{~mol} \%)$ on a range of clickable protected and non-protected mono- and disaccharides. Once initiated, the reaction can be stopped at any time on introducing air into the reaction medium. Deoxygenation followed by irradiation restores the activity, making the copper(II)-DMEDA complex a switchable catalyst of practical value.

\section{Introduction}

The search for catalysts that can be activated by using daylight, such as copper(II)-DMEDA ( $N, N^{\prime}$-dimethylethylendiamine) complex 1 described herein (Scheme 1), attracts considerable interest, with solar photons being considered as ideal "reagents". ${ }^{[1,2]}$ Besides the economical and practical advantages that the use of daylight as an energy source represents, exploiting light as a stimulus to activate a catalyst offers other key benefits, including potential spatial and temporal control over the catalytic event and convenient handling of stable precatalysts under ambient conditions, as well as the possibility to control the onset of the generated catalytic species by varying the irradiation parameters, typically the irradiation time, power, and excitation wavelength. ${ }^{[3,4]}$ Recently, photoredox copper(I) catalysis has emerged as a powerful tool for the formation of $\mathrm{C}-\mathrm{C}_{,}^{[5-7]} \mathrm{C}-\mathrm{N},{ }^{[8-11]} \mathrm{C}-\mathrm{S},{ }^{[12]}$ or $\mathrm{C}-\mathrm{O}^{[13]}$ bonds. In such photocata-

[a] R. Beniazza, R. Lambert, Dr. L. Harmand, S. Denisov, N. D. McClenaghan Dr. D. Lastécouères, Dr. J. M. Vincent

Université de Bordeaux, Institut des Sciences Moléculaires UMR CNRS 5255, 351, Crs de la Libération, 33405 Talence Cedex (France)

E mail:jm.vincent@ism.u bordeaux1.fr

[b] F. Molton, Dr. C. Duboc

Univ. Grenoble Alpes, DCM UMR CNRS 5250, 38000 (Grenoble)

[c] S. Denisov, Dr. G. Jonusauskas

Université de Bordeaux, Laboratoire Ondes et Matière d'Aquitaine, UMR CNRS 5798, 351 Crs de la Libération, 33405 Talence (France) lytic systems continuous light irradiation is employed to generate, from an inactive copper(I) complex, a catalytically active photoexcited copper(I) species, which is able to reduce alkyl or aryl halides through single-electron-transfer processes to generate alkyl or aryl radicals. For one of these catalytic systems, it was also shown that sunlight can be used instead of lamp irradiation. ${ }^{[6]}$
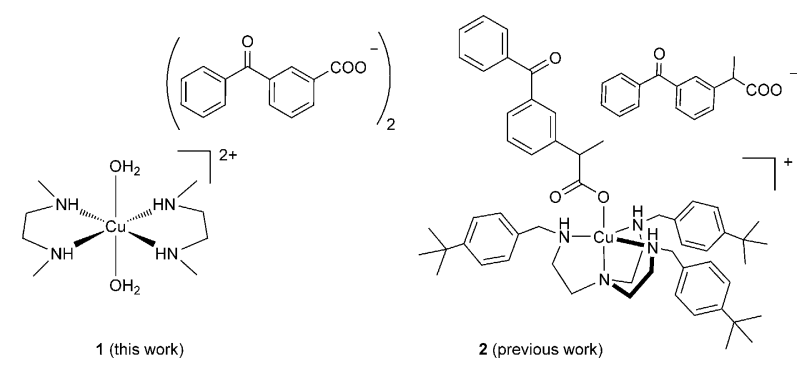

Scheme 1. Structures of the photoreducible complexes $\mathbf{1}$ and $\mathbf{2}$.

Inspired by the early work of Chow and Buono-Core, ${ }^{[14-17]}$ we recently proposed a complementary strategy for copper-catalyst activation mediated by light. Photoinduced electron transfer (PET) to a metal cation was introduced as a way to generate a catalytically active low-valent copper(l) species from the corresponding inactive high-valent copper(II) precatalyst. ${ }^{[18,19]}$ We reported that a copper(II)-tren (tren $=$ tris(2-aminoethyl)amine) precatalyst 2 (Scheme 1), in which a benzophenone-like photosensitizer is introduced in the guise of the ketoprofenate 
carboxylate counterion, can be efficiently photoreduced upon irradiation at $365 \mathrm{~nm}$. This photoreduction process was exploited to photogenerate, on-demand, a highly reactive catalyst for the copper(I)-catalyzed alkyne-azide cycloaddition (CuAAC), ${ }^{[20,21]}$ a click reaction now recognized as one of the most useful chemical transformations employed in all fields of the chemical sciences. ${ }^{[22,24]}$ The irradiation, from a standard $4 \mathrm{~W}$ thin-layer chromatography (TLC) lamp, was shown to mediate a highly efficient photoinduced electron-transfer process, leading to fast copper(II) to copper $(I)$ reduction $\left(\Phi_{\text {red }}=0.17\right.$ in $\mathrm{MeOH}$ ), the final electron source being the solvent, typically $\mathrm{MeOH}, \mathrm{THF}$, or toluene.

A related strategy developed by Bowman and co-workers, consists of exploiting photoinitiators, which upon irradiation generate radicals that reduce copper(II) ions to copper(I). ${ }^{[25-27]}$ The potential of such reactivity was demonstrated in the photopatterning of surfaces ${ }^{[25]}$ and polymer synthesis. ${ }^{[26,27]}$ Very recently, the same group reported a copper(II) precatalyst with an acylphosphinate radical photoinitiator counteranion, which upon activation by light irradiation proved to be an effective catalyst for atom-transfer radical-polymerization (ATRP) and CUAAC reactions. ${ }^{[28]}$ The irradiations were conducted by using visible light (typically $5-10 \mathrm{~mW} \mathrm{~cm}^{-2}$ in the $400-500 \mathrm{~nm}$ wavelength region), a possible limitation of such a system is being that the reduction efficiency is moderate, with a maximum of $\approx 50 \%$ generation of the copper $(\mathrm{I})$ species. Examples of "direct" copper(II) to copper(I) photoreductions applied to photoinduced CuAAC reactions have also been reported. ${ }^{[29-31]}$ Beyond the copper-catalyzed systems it should be emphasized that a range of light-induced click reactions have been developed. ${ }^{[32]}$ It is noteworthy that the copper(II) ions of a laccase protein could be effectively reduced through a $\mathrm{Zn}$-porphyrin photosensitized process, the generated copper(I) species could then mediate the four-electron reduction of $\mathrm{O}_{2}$ into water. ${ }^{[33]}$

By exploiting extremely efficient photochemical reactions, one can envisage the development of a photosensitized copper(II) to copper(I) reduction process occurring effectively by using sunlight. We describe herein the synthesis, full characterization, photoreduction properties, and catalytic activity for the CUAAC reaction of the copper(II)-DMEDA complex 1 (Scheme 1). Copper-DMEDA complexes are well-known and versatile coordination compounds that have been shown to exhibit excellent catalytic properties for important chemical transformations, ${ }^{[34]}$ in particular for reactions catalyzed by copper(I) species. ${ }^{[34-38]}$ The DMEDA ligand is structurally simple, commercially available, and inexpensive, making it valuable from a practical point of view. Moreover, considering the prominent role of copper(I)-catalyzed processes in modern chemistry, ${ }^{[34,39-41]}$ the design of a photoreducible copper(II)DMEDA precatalyst emerged as a target of choice.

\section{Results and Discussion}

\section{Synthesis and characterization of precatalyst 1}

The photosensitizer in $\mathbf{1}$ was introduced through the copper carboxylate counterion, a synthetically convenient strategy to link the benzophenone chromophore to the copper complex. Instead of the ketoprofenate anion, present in $\mathbf{2}$ (a chiral antiinflammatory drug, for which photostability issues have been identified) ${ }^{[42]}$ the 3-benzoylbenzoate counterion is favored in 1. The complex, $\left[\mathrm{Cu}(\mathrm{DMEDA})_{2}\left(\mathrm{H}_{2} \mathrm{O}\right)_{2}\right]$ (3-benzoylbenzoate) ${ }_{2} \mathbf{1}$, was prepared by reacting $\mathrm{CuOTf}_{2}(\mathrm{OTf}=$ trifluoromethanesulfonate) with two equivalents of the sodium salt of the commercially available 3-benzoylbenzoic acid in water, leading to quantitative precipitation of $\left[\mathrm{Cu}(3-\text { benzoylbenzoate })_{2}\left(\mathrm{H}_{2} \mathrm{O}\right)\right]$ as a blue/green powder. When [Cu(3-benzoylbenzoate) $\left.)_{2}\left(\mathrm{H}_{2} \mathrm{O}\right)\right]$ reacted with two equivalents of DMEDA in THF/ $\mathrm{H}_{2} \mathrm{O}$, the solution turned from light blue to deep blue. Slow diffusion of diethyl ether vapor led to the formation of purple crystals of 1, which were isolated in $94 \%$ yield (Scheme 2 ). Single-crystal X-ray dif-

$$
\begin{array}{llll}
\mathrm{RCOONa}_{2 \text { equiv }} & \begin{array}{l}
\mathrm{CuOTf}_{2} \\
\text { 1 equiv }
\end{array} & \begin{array}{l}
\text { 1) } \mathrm{H}_{2} \mathrm{O}, \mathrm{rt} \\
\mathrm{DMEDA}(2.2 \text { equiv })
\end{array}
\end{array} } &{1} \\
{\text { in } \mathrm{THF} / \mathrm{H}_{2} \mathrm{O}, \mathrm{rt}} &{94 \%}
\end{array}
$$

Scheme 2. Synthesis of complex 1.

fraction analysis revealed that $\mathbf{1}$ has a monomeric structure (Figure 1) with a distorted octahedral geometry with the four nitrogen atoms in the equatorial plane (average $d_{\mathrm{Cu} \cdots \mathrm{N}} 2.045 \AA$ ), while two elongated $\mathrm{Cu}-\mathrm{OH}_{2}$ bonds are present in the axial positions (average $d_{\text {Cun.. }} 2.603 \AA$ ). Remarkably, the carboxylate anions are not directly bound to the copper(II) ion, but interact with the $\left[\mathrm{CuDMEDA}\left(\mathrm{OH}_{2}\right)_{2}\right]^{2+}$ dication through an extended network of hydrogen bonds, with each oxygen atom of the carboxylates participating in two hydrogen bonds to the hydrogen atoms of water $\left(d_{\mathrm{CO}-. . \mathrm{HO}} 1.833 \AA\right)$ and the secondary amine $\left(d_{\mathrm{CO} . . . \mathrm{HN}} 2.006 \AA\right)$ ligands (Figure 1).

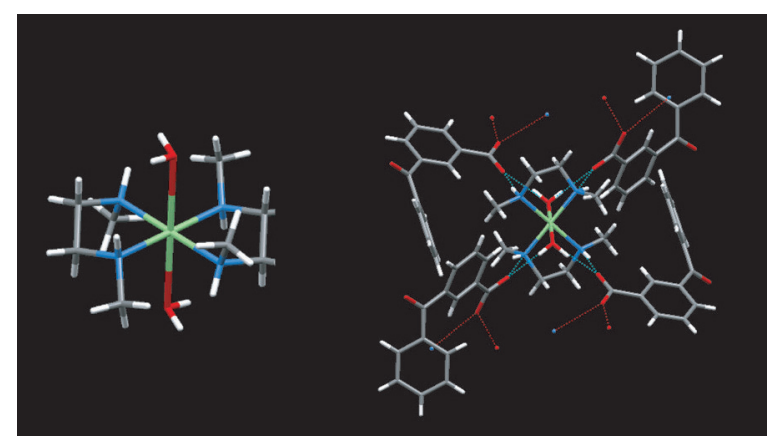

Figure 1. Molecular structures of the $\left[\mathrm{CuDMEDA}\left(\mathrm{OH}_{2}\right)_{2}\right]^{2+}$ dication in 1 , and view showing the hydrogen bond interactions between the dication and the four surrounding benzoates. $\mathrm{Cu}$, green; $\mathrm{C}$, grey; $\mathrm{H}$, white; $\mathrm{N}$, blue; $\mathrm{O}$, red.

\section{Photoreduction and photophysical studies}

Figure 2 a shows the UV/Vis spectra recorded when a deoxygenated (by multiple freeze-pump-thaw cycles in a sealed cell) solution of $1(1.9 \mathrm{~mm})$ in THF $(3 \mathrm{~mL})$ was irradiated at $365 \mathrm{~nm}$ by using a $4 \mathrm{~W}$ TLC lamp (the reductions were conducted in a room in which the only source of light was the TLC lamp). A 

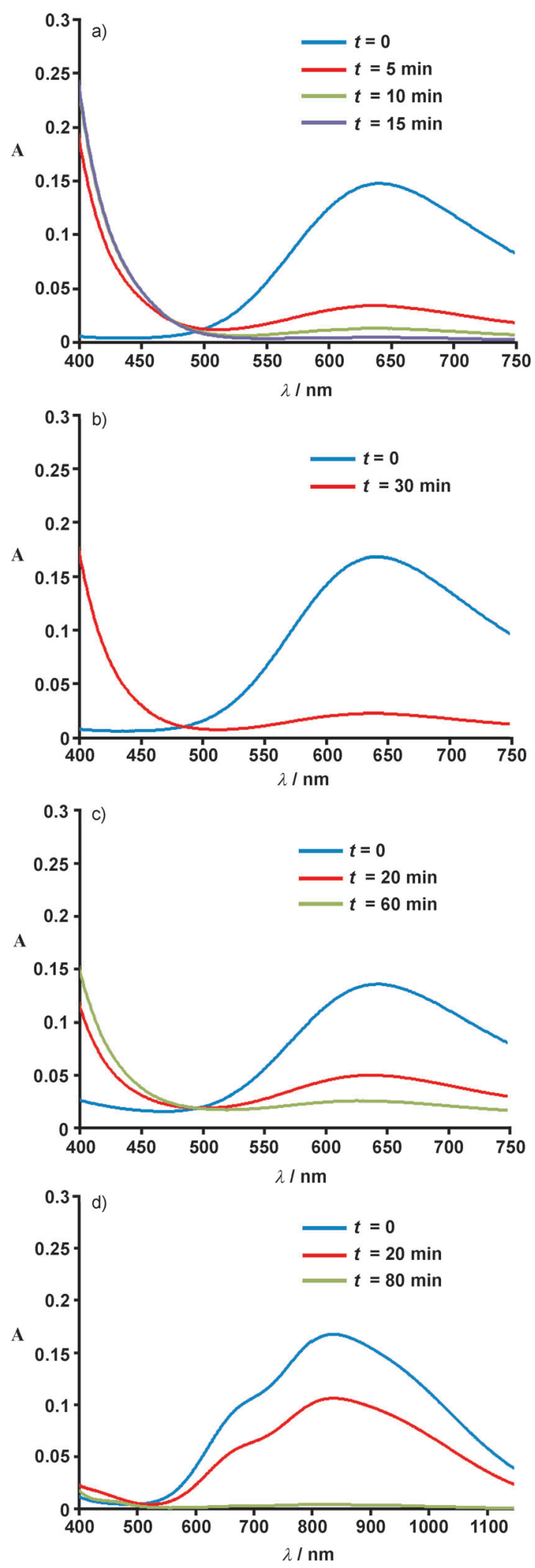

Figure 2. Evolution of the UV/Vis spectra of deaerated (freeze pump thaw degassed, sealed quartz cuvettes) $1.9 \mathrm{~mm}$ THF solutions of complexes 1 and 2 under different illumination conditions ( $\mathrm{A}=$ absorbance): a) Complex $\mathbf{1}$ irra diated at $365 \mathrm{~nm}$ by using a TLC lamp; b) Complex 1 under direct sunlight illumination (sunny day); c) Complex 1 under daylight illumination (rainy day); d) Complex 2 under daylight illumination (rainy day). very fast reduction occurs, with $a \approx 80 \%$ decrease of the absorption intensity at $640 \mathrm{~nm}$ being observed after 5 min irradiation. The disappearance of this low-energy absorption band, which is ascribed to a $\mathrm{d}-\mathrm{d}$ transition, is conducive with reduction of the initial copper(II) ion. Complete reduction was achieved in $\approx 15 \mathrm{~min}$, affording a colorless THF solution.

The reduction was confirmed by EPR studies, which showed the fast disappearance of the copper(II) signal when an EPR tube containing a deaerated THF solution of 1 was irradiated (Figure 3).

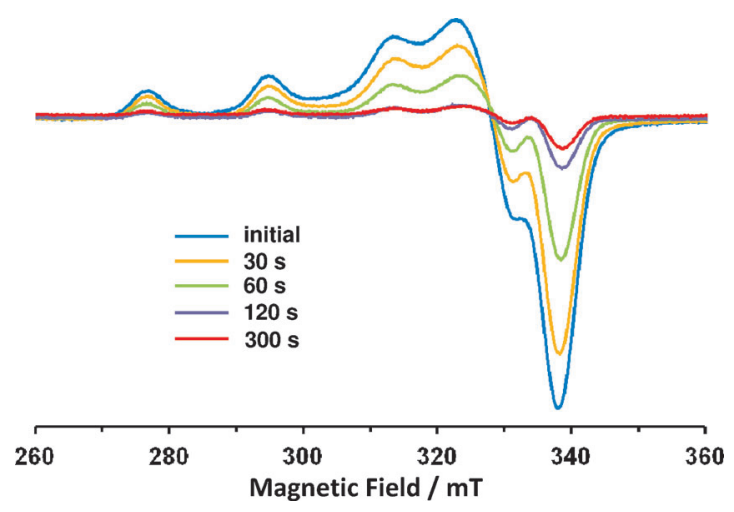

Figure 3. Evolution of the EPR spectra ( $X$ band, $100 \mathrm{~K}$ ) of deaerated (Ar bub bling) $1 \mathrm{~mm}$ THF solution of complex 1 when irradiated at $365 \mathrm{~nm}$ by using a TLC lamp $\left(g_{x}: 2.216, g_{y}=2.055, g_{z}=2.045, A_{x}(C u)=565 \mathrm{MHz}\right)$.

Importantly, a photoreduction quantum yield approaching unity was determined for a degassed $1.9 \mathrm{~mm}$ solution of 1 in THF ( $\lambda_{\mathrm{ex}}=365 \mathrm{~nm}$, ferrioxylate actinometry using a microversion of Hatchard and Parker's method, based on six separate experiments), suggesting that essentially one copper(II) atom is reduced for every photon absorbed. ${ }^{[43]}$ The inherently high values and consequent difficulty of sample preparation and manipulation hampers more precise determination of this value. In $\mathrm{MeOH}$, a good $\mathrm{H}$-donating solvent, the reduction is very fast with typically a $70 \%$ decrease of the absorption band at $610 \mathrm{~nm}$ observed within $5 \mathrm{~min}$ of irradiation (spectra provided in the Supporting Information). However, it should be noted that in $\mathrm{MeOH}$ the appearance of colloidal copper nanoparticles was rapidly observed (after $\approx 5-7$ min irradiation) as evidenced through the diagnostic plasmon resonance absorption bands in the visible spectral region. This finding means that in the absence of reactants that trap the copper(I) species, copper(0) is rapidly generated in $\mathrm{MeOH}$, through a copper(I) photoreduction process or through copper(I) disproportionation. In $\mathrm{MeCN}$ and $\mathrm{CH}_{2} \mathrm{Cl}_{2}$, two much less efficient $\mathrm{H}$-donating solvents, the reduction process is still observed, with complete reduction in $\approx 40 \mathrm{~min}$ and $70 \mathrm{~min}$, respectively (see the Supporting Information for spectra).

Quantum yields of copper reduction in 1 of 0.22 and 0.03 were established in $\mathrm{MeOH}$ and $\mathrm{MeCN}$, respectively.

In light of the remarkably high photoreduction quantum yield measured for $\mathbf{1}$, it was anticipated that effective reduction could proceed under daylight illumination. As shown in 
Figure $2 \mathrm{~b}$, when a deoxygenated THF solution of $\mathbf{1}$ in a sealed cell is positioned behind a window and exposed to direct sunlight, $\approx 85 \%$ of the copper(II) species was reduced in $30 \mathrm{~min}$. As expected for a photochemical process driven by daylight, the weather has a significant influence on the reduction kinetics, a reduction of $\approx 80 \%$ in 60 min typically being observed for 1 when exploiting the light of a rainy day, under otherwise analogous conditions. Under the same conditions (experiments conducted in parallel) the daylight photoreduction of complex 2 proceeded well, despite a lowered efficiency. After 20 min of illumination, reduction of 63 and $37 \%$ of 1 and 2 were measured, respectively. A colorless, fully reduced solution of $\mathbf{2}$ was obtained after $\approx 80 \mathrm{~min}$.

Similar to the observations with complex 2, photoreduced complex $\mathbf{1}$ is extremely sensitive to $\mathrm{O}_{2}$; instantaneous recoloration was observed when air was bubbled into a colorless solution of reduced 1 . The UV/Vis spectrum of the reoxidized solution is similar to the initial spectrum, nonetheless with a significant increase of the absorption observed between 400 and $500 \mathrm{~nm}$ (Figure S2). When the reoxidized solution is deoxygenated (Ar bubbling) and then irradiated, reduction occurs at a rate comparable to that of the initial reduction. EPR experiments (Figure S3) confirmed such behavior, showing that after air reoxidation a copper(II) complex with slightly different EPR signal is formed, affording $a \approx 60: 40$ ratio between the starting complex 1 and the new species. Importantly, both species are reduced to copper(I) species upon irradiation, as shown by the disappearance of both signals. These results show that the photoreduction/oxidation process exhibits a satisfactory degree of reversibility, necessary to achieve switching ON/OFF for multiple cycles during catalysis.

In terms of the photophysical properties of $\mathbf{1}$ in $\mathrm{MeCN}$, $\mathrm{MeOH}$, and THF, transient absorption spectroscopy provides a convenient tool to follow the temporal evolution of the nonemissive initially formed benzophenone triplet state $\left(\lambda_{\max }=\right.$ 533,526 , and $520 \mathrm{~nm}$ in $\mathrm{MeCN}, \mathrm{MeOH}$, and THF, respectively), which is formed on the sub-nanosecond timescale upon photoexcitation of this photosensitizer. ${ }^{[18,44]}$ Studies of the change of this excited-state absorption gives information about the first steps in the generation of the catalytically active copper(I) species, which is unambiguously evidenced by steady-state spectrophotometry and EPR studies, as well as the intercomponent communication. At similar concentrations of 1 , the rate of triplet transient absorption change in $\mathrm{MeCN}$ is faster than that in $\mathrm{MeOH}$ ( $\tau=84 \mathrm{~ns}, 2.4 \mathrm{~mm}, \mathrm{MeCN} ; \tau=140 \mathrm{~ns}, 2.5 \mathrm{~mm}, \mathrm{MeOH}$ ), despite an approximately ten-fold higher quantum yield of reduction for the latter, which may suggest a non-direct monoelectronic reduction of copper from the benzophenone-like triplet state, and hence an intervening state in the reduction process (Figure S6-S8). In THF (Figure S5 and S8), a faster initial rate of triplet change was obtained ( $\tau=9 \mathrm{~ns}, 2.8 \mathrm{~mm}$ ), and was similarly observed with the 3-benzoylbenzoic acid itself ( $\tau=$ $7 \mathrm{~ns}, 2.9 \mathrm{~mm}$ ), suggesting a benzophenone-localized process or specific interaction with the THF solvent as key initial steps. On longer timescales, some yellow photoproduct formation (time constant $=53 \mu \mathrm{s}$, see Figure S9) is observed on irradiating complex 1 or the 3-benzoylbenzoic acid alone, denoting a minor photochemical side reaction, which is more clearly visible in THF, and reverts in minutes to the initial product.

Information on the interaction of the excited anionic moiety, and the ground-state inorganic moiety in solution, may also be revealed by the lifetime of the triplet absorption band. The inorganic cation and benzophenone anion pairing may be expected to be dependent on both the concentration of 1 and the solvent nature. Figure 4 shows the benzophenone-like trip-

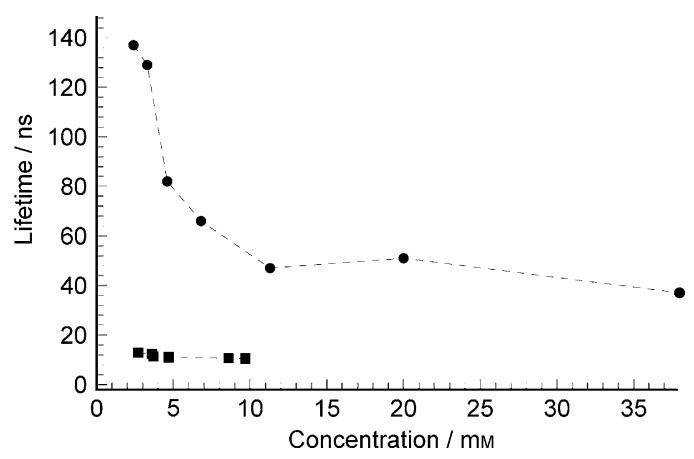

Figure 4. Benzophenone like triplet state lifetime as a function of concentra tion of 1 in degassed methanol (dots) and degassed THF (squares). Excita tion at $355 \mathrm{~nm}$.

let lifetime of 1 as a function of concentration in both $\mathrm{MeOH}$ and THF, with solubility and detectable signal dictating the higher and lower concentration values, respectively. Triplet quenching can depend on a number of solvent parameters, making direct comparison of $\mathrm{MeOH}$ and THF difficult. However, it is clear that a greater concentration dependence is observed in $\mathrm{MeOH}$ than in THF. This can be rationalized in terms of the higher capacity of more polar $\mathrm{MeOH}$ to solvate the charged species compared with that of THF (relative polarities of 0.762 and 0.207$).{ }^{[4]}$ This would limit the contact of the photosensitizer with the inorganic moiety during the lifetime of the excited state and hence quenching, which is significantly enhanced in $\mathrm{MeOH}$ on increasing the concentration of $\mathbf{1}$. On the other hand, in THF the triplet is strongly quenched at $2 \mathrm{~mm}$ and is only slightly affected on increasing concentration. This is consistent with either a direct THF solvent reaction or a stronger association between the photoactive anion and copper-containing cation, and shows that for this type of system attention should be paid to the absolute catalyst concentration in a given solvent.

\section{Catalytic properties}

To assess the switching properties of precatalyst 1 and the reactivity of the photogenerated copper(I) species, protected and non-protected mono- and disaccharides were chosen as they represent a prominent class of clickable substrates. Catalytic reactions were typically conducted in NMR tubes, at $0.5 \mathrm{~mol} \%$ precatalyst loading and $0.33 \mathrm{M}$ reactant concentration, affording a convenient way to follow the reaction kinetics. The reaction mixtures were deoxygenated by $\mathrm{Ar}$ bubbling (15 $\mathrm{min}$ ) keeping the tube protected from light (by using alu- 


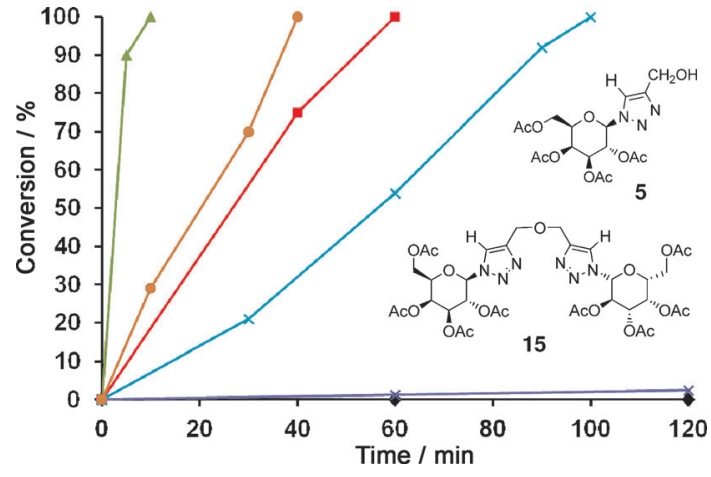

Figure 5. Reaction profiles for the formation of triazoles $\mathbf{5}$ and $\mathbf{1 5}$ followed by ${ }^{1} \mathrm{H}$ NMR spectroscopy under different illumination conditions (see experi mental conditions in the text): Profiles for compound 15, obtained by using TLC lamp irradiation (green), daylight illumination (red) or from an NMR tube kept in the dark (black); profiles for compound $\mathbf{5}$ obtained by using TLC lamp irradiation (orange), daylight illumination (blue) or from an NMR tube kept in the dark (purple)

minum foil) and, after a given time, exposed to daylight behind a window (direct sunlight), or $10 \mathrm{~min}$ of the $365 \mathrm{~nm}$ UV light of a TLC lamp $(4 \mathrm{~W})$ positioned $\approx 1 \mathrm{~cm}$ from the NMR tube. Figure 5 shows the reaction profiles for the formation of compounds 15 and 5 under various illumination conditions. When 1 was activated by TLC lamp irradiation, the reaction proceeded very rapidly with complete conversion obtained in $\approx 10 \mathrm{~min}$ and $40 \mathrm{~min}$ for 15 and 5 , respectively. Interestingly, no latency period was observed, in agreement with the fast generation of a highly reactive copper(I) species. In the absence of light, the background activity of 1 was very low, with typically less than $5 \%$ of triazoles formed within 2-4 h. Importantly, under daylight illumination the reaction proceeded very well, with complete conversion reached within $\approx 40 \mathrm{~min}$ and 100 min for 15 and 5 , respectively.

The switching properties of 1 were then evaluated for the peracetylated $\beta$-D-galactopyranosyl azide $\mathbf{4}$ and propargyl alcohol 3 , in $\left[D_{8}\right]$ THF. As shown in Figure 6 , the activity of $\mathbf{1}$ is rapidly turned on upon irradiation at $365 \mathrm{~nm}$. Once switched on
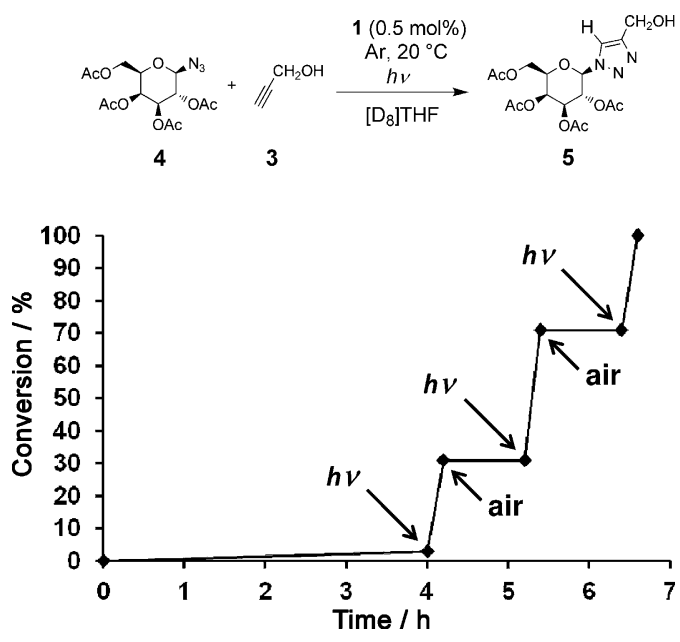

Figure 6. Reaction profile for the formation of triazole 5 followed by ${ }^{1} \mathrm{H}$ NMR spectroscopy and applying external stimuli. the reaction can be stopped at any time by bubbling air into the reaction medium because of an extremely fast copper(I) to copper(II) oxidation by molecular oxygen. Deoxygenation ( $\mathrm{Ar}$ bubbling), followed by irradiation (10 $\mathrm{min}$ ) fully restores the catalytic activity. The robustness of this reversible process is satisfactory, the reaction having been switched ON/OFF three times in the same run, without significantly changing the kinetics in the ON state. It should be noted that when the reactions are conducted in $\mathrm{CD}_{3} \mathrm{OD}$, the triazoles were obtained as a mixture of hydrogenated and deuterated compounds, owing to partial terminal alkyne H/D exchange during catalysis (see ${ }^{1} \mathrm{H}$ and ${ }^{13} \mathrm{C}$ NMR provided in the Supporting Information).

The high reactivity of the photogenerated copper(I) species was exploited to prepare a range of triazoles 6-19 (Scheme 3) All reactions were conducted in NMR tubes at low catalyst loading $(0.5 \mathrm{~mol} \%)$ in $\mathrm{CD}_{3} \mathrm{OD}, \mathrm{CD}_{3} \mathrm{OD} / \mathrm{D}_{2} \mathrm{O}$, or $\left[\mathrm{D}_{8}\right] \mathrm{THF}$ to ensure complete solubility of the reactants $(0.25 \mathrm{mmol})$. The reactions reached full conversion (followed by ${ }^{1} \mathrm{H}$ NMR spectroscopy) at the time indicated in Scheme 3. The triazoles 6-19 were obtained in good to excellent isolated yields with reaction times ranging from $10 \mathrm{~min}$ to $8 \mathrm{~h}$.

Finally, the synthesis of the unprotected disaccharide 19 was conducted on a $5 \mathrm{mmol}$ scale in a round-bottom flask $(30 \mathrm{~mL}$ of $\mathrm{CH}_{3} \mathrm{OH}$ ) at $0.5 \mathrm{~mol} \%$ precatalyst loading under daylight irradiation (sunny day). Under these conditions, $1.94 \mathrm{~g}$ of the disaccaharide was isolated after $3 \mathrm{~h}$ of reaction ( $92 \%$ yield). When the same reaction was conducted on the same scale in the dark, $<5 \%$ conversion was measured after $3 \mathrm{~h}$ (Scheme 4 ).

\section{Conclusion}

Taking advantage of an extremely efficient benzophenone-sensitized PET process, the copper(II) to copper(I) photoreduction of complex 1 proceeds under daylight illumination with unprecedented efficiency. The photogenerated copper $(\mathrm{I})$ species is extremely reactive for the CuAAC reaction, as demonstrated through the preparation of mono-, di- and tetrasaccharides, full conversion being achieved at low catalyst loading with short to moderate reaction times, typically in THF or $\mathrm{MeOH}$ solvents. Either ambient light or TLC lamp irradiation at $365 \mathrm{~nm}$ can be conveniently used to activate the copper(II) precatalyst, due to the extremely high photoreduction quantum yields. Deaerated solutions (Ar bubbling) are required for the reactions to proceed because the photogenerated copper(I) species is extremely sensitive to dioxygen. Such reactivity can be exploited to turn OFF/ON the catalyst activity on-demand. Once initiated by light, the reaction can be stopped by introducing air into the reaction mixture, and deoxygenation followed by irradiation enables reinitiation of the reaction with similar initial rates. Considering the ease of preparation, the remarkable efficiency of its photoreduction under ambient light, and the reactivity of the photogenerated copper(I) species, precatalyst 1 has strong potential for applications, not only in CuAAC reactions, but also in other important copper(I)-catalyzed processes. Studies along these lines are currently in progress. 


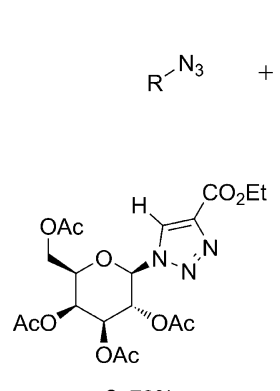

6, $79 \%$

(THF-d8, $90 \mathrm{~min}$ )<smiles>CC(=O)OC[C@H]1O[C@@H](n2nnc(Cc3ccccc3)c2C)[C@H](OC(C)=O)[C@@H](OC(C)=O)[C@@H]1OC(C)=O</smiles>

9, $93 \%$ (THF-d8, $30 \mathrm{~min}$ )<smiles>OCc1nnn([C@@H]2O[C@H](CO)[C@@H](O)[C@H](O)[C@H]2O)c1P</smiles>

$12,91 \%$ $\left(\mathrm{CD}_{3} \mathrm{OD}, 30 \mathrm{~min}\right)$

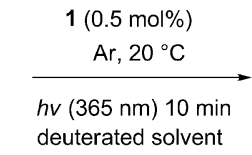<smiles>CC(=O)OC[C@H]1O[C@@H](n2nnc(C)c2OC(C)=O)[C@H](OC(C)=O)[C@@H](OC(C)=O)[C@@H]1OC(C)=O</smiles>

7, $89 \%$

(THF-d8, $120 \mathrm{~min}$ )

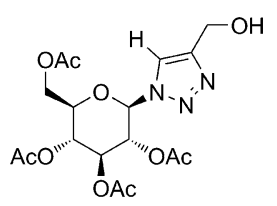

$10,85 \%$ (THF-d8, $120 \mathrm{~min}$ )<smiles>OCc1nnn(C[C@H]2O[C@H](O)[C@@H](O)[C@H](O)[C@H]2O)c1[PH]</smiles>

$13,74 \%$

$\left(\mathrm{CD}_{3} \mathrm{OD}, 8 \mathrm{~h}\right)$
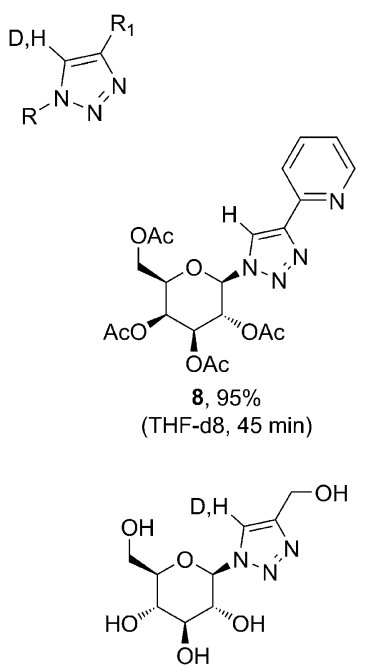

$11,87 \%$ $\left(\mathrm{CD}_{3} \mathrm{OD}, 2 \mathrm{~h}\right)$

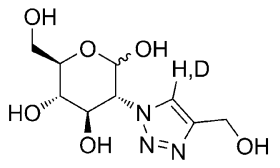

14, $90 \%$ $\left(\mathrm{CD}_{3} \mathrm{OD}, 3 \mathrm{~h}\right)$

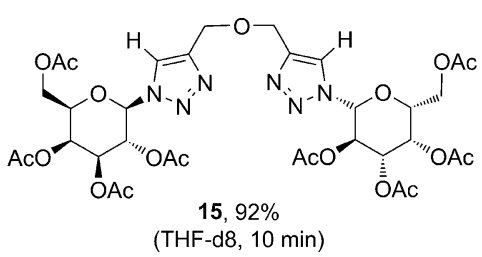

(THF-d8, $10 \mathrm{~min}$ )

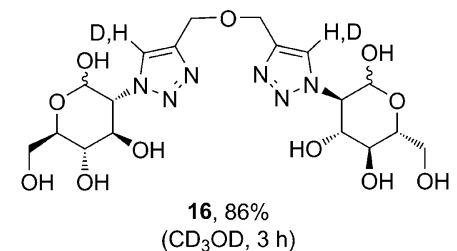

$\left(\mathrm{CD}_{3} \mathrm{OD}, 3 \mathrm{~h}\right)$

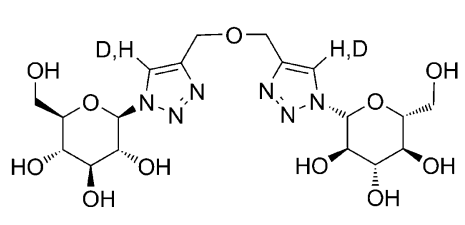

$17,94 \%$

$\left(\mathrm{CD}_{3} \mathrm{OD}, 10 \mathrm{~min}\right)$

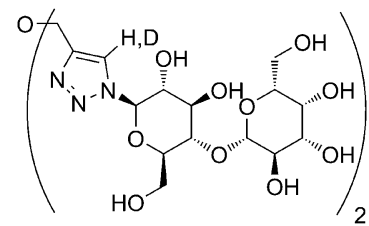

18, $89 \%$ $\left(\mathrm{CD}_{3} \mathrm{OD} / \mathrm{D}_{2} \mathrm{O} 3 / 1,120 \mathrm{~min}\right)$

Scheme 3. Structures and reaction yields for triazoles 619 .<smiles>N[C@H]1O[C@H](CO)[C@@H](O)[C@H](O)[C@H]1O</smiles>

20<smiles>C#CCO[C@H]1O[C@H](CO)[C@@H](O)[C@H](O)[C@H]1O</smiles>

21

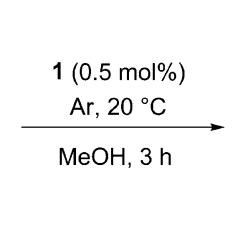

reaction under daylight: reaction in the dark:<smiles>OC[C@H]1O[C@@H](OCc2cn([C@H]3O[C@H](CO)[C@@H](O)[C@@H](O)[C@H]3O)nn2)[C@H](O)[C@@H](O)[C@@H]1O</smiles>

$92 \%$ isolated yield $(1.94 \mathrm{~g})$

$<5 \%$ conversion

Scheme 4. Preparative scale synthesis of 19 by using sunlight.

\section{Acknowledgements}

The University of Bordeaux, the CNRS, the Région Aquitaine, the ANR (ANR-13-BS07-0006-01), the European Research Coun-

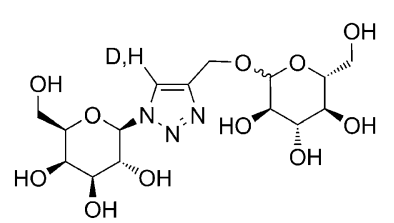

$19,91 \%$ $\left(\mathrm{CD}_{3} \mathrm{OD}, 20 \mathrm{~min}\right)$ cil (FP7/2008-2013) ERC grant agreement no. 208702 and IRRPE CNRS 3443 are gratefully acknowledged for their financial support.

Keywords: benzophenone . click chemistry - copper catalysts - photoactivation . photoinduced electron transfer

[1] D. Ravelli, D. Dondi, M. Fagnoni, A. Albini, Chem. Soc. Rev. 2009, 38, 1999.

[2] M. Majek, A. Jacobi von Wangelin, Angew. Chem. 2013, 125, 6033; Angew. Chem. Int. Ed. 2013, 52, 5919.

[3] U. Lüning, Angew. Chem. 2012, 124, 8285; Angew. Chem. Int. Ed. 2012, 51, 8163.

[4] R. S. Stoll, S. Hecht, Angew. Chem. 2010, 122, 5176; Angew. Chem. Int. Ed. 2010, 49, 5054.

[5] A. Sagadevan, K. C. Hwang, Adv. Synth. Catal. 2012, 354, 3421.

[6] M. Pirtsch, S. Paria, T. Matsuno, H. Isobe, O. Reiser, Chem. Eur. J. 2012, 18, 7336.

[7] A. Baralle, L. Fensterbank, J. P. God dard, C. Ollivier, Chem. Eur. J. 2013, 19, 10809.

[8] S. E. Creutz, K. J. Lotito, G. C. Fu, J. C. Peters, Science 2012, 338, 647.

[9] A.C. Bissember, R. J. Lundgren, S. E. Creutz, J.C. Peters, G. C. Fu, Angew. Chem. 2013, 125, 5233; Angew. Chem. Int. Ed. 2013, 52, 5129.

[10] D. T. Ziegler, J. Choi, J. M. Muñoz Molina, A.C. Bissember, J.C. Peters, G. C. Fu, J. Am. Chem. Soc. 2013, 135, 13107.

[11] H. Q. Do, S. Bachman, A. Bissember, J. C. Peters, G. C. Fu, J. Am. Chem. Soc. 2014, 136, 2162.

[12] C. Uyeda, Y. Tan, G. C. Fu, J.C. Peters, J. Am. Chem. Soc. 2013, $135,9548$.

[13] Y. Tan, J. M. Muñoz Molina, G. C. Fu, J. C. Peters, Chem. Sci. 2014, 5, 2831.

[14] Y. L. Chow, G. E. Buono Core, Can. J. Chem. 1983, 61, 795.

[15] Y. L. Chow, G. E. Buono Core, Can. J. Chem. 1983, 61, 801.

[16] Y. L. Chow, G. E. Buono Core, J. Am. Chem. Soc. 1982, 104, 3770.

[17] Y. L. Chow, G. E. Buono Core, J. Am. Chem. Soc. 1986, 108, 1234.

[18] L. Harmand, S. Cadet, B. Kauff mann, L. Scarpantonio, P. Batat, G. Jonusauskas, N.D. McClenaghan, D. Lastécouères, J. M. Vincent, Angew. Chem. 2012, 124, 7249; Angew. Chem. Int. Ed. 2012, 51, 7137. [19] L. Harmand, R. Lambert, L. Scarpantonio, N. D. McClenaghan, D. Lasté couères, J. M. Vincent, Chem. Eur. J. 2013, 19, 16231. 
[20] V. Rostovtsev, L. G. Green, V. V. Fokin, K. B. Sharpless, Angew. Chem 2002, 114, 2708; Angew. Chem. Int. Ed. 2002, 41, 2596.

[21] C. W. Tornøe, C. Christensen, M. Meldal, J. Org. Chem. 2002, 67, 3057.

[22] Special issue on applications of click chemistry (Ed.: M. G. Finn, V. Fokin): Chem. Soc. Rev. 2010, 39, 1231.

[23] M. Meldal, C. W. Tornøe, Chem. Rev. 2008, 108, 2952.

[24] S. Díez González, Catal. Sci. Technol. 2011, 1, 166.

[25] B. J. Adzima, Y. Tao, C. J. Kloxin, C. A. DeForest, K. S. Anseth, C. N. Bowman, Nat. Chem. 2011, 3, 258.

[26] A. A. Alzahrani, A. h. Erbse, C. N. Bowman, Polym. Chem. 2014, 5, 1874.

[27] T. Gong, B. J. Adzima, N. h. Baker, C. N. Bowman, Adv. Mater. 2013, 25, 2024.

[28] T. Gong, B. J. Adzima, C. N. Bowman, Chem. Commun. 2013, 49, 7950

[29] M. A. Tasdelen, Y. Yagci, Tetrahedron Lett. 2010, 51, 6945.

[30] M. A. Tasdelen, G. Yilmaz, B. Iskin, Y. Yagci, Macromolecules 2012, 45, 56.

[31] B. Sandmann, B. Happ, J. Vitz, M. D. Hager, P. Burtscher, N. Moszner, U. S. Schubert, Polym. Chem. 2013, 4, 3938.

[32] M. A. Tasdelen, Y. Yagci, Angew. Chem. 2013, 125, 6044; Angew. Chem. Int. Ed. 2013, 52, 5930 .

[33] T. Lazarides, I. V. Sazanovich, A. J. Simaan, M. C. Kafentzi, M. Delor, Y Mekmouche, B. Faure, M. Réglier, J. A. Weinstein, J. Am. Chem. Soc 2013, 135, 3095.
[34] For a review, see: D. S. Surry, S. L. Buchwald, Chem. Sci. 2010, 1, 13

[35] P. F. Larsson, C. Bolm, P. O. Norrby, Chem. Eur. J. 2010, 16, 13613.

[36] J. W. Tye, Z. Weng, A. M. Johns, C. D. Incarvito, J. F. Hartwig, J. Am. Chem. Soc. 2008, 130, 9971.

[37] Y. Liu, Y. Bai, J. Zhang, Y. Li, J. Jiao, X. Qi, Eur. J. Org. Chem. 2007, 6084

[38] S. Potratz, A. Mishra, P. Bäuerle, Beilstein J. Org. Chem. 2012, 8, 683.

[39] S. R. Chemler, Science 2013, 341, 624.

[40] G. Evano, N. Blanchard, M. Toumi, Chem. Rev. 2008, 108, 3054

[41] S. V. Ley, A. W. Thomas, Angew. Chem. 2003, 115, 5558; Angew. Chem. Int. Ed. 2003, 42, 5400; Angew. Chem. Int. Ed. 2003, 42, 5400.

[42] G. Cosa, M. Lukeman, J. C. Scaiano, Acc. Chem. Res. 2009, 42, 599.

[43] M. Montalti, A. Credi, L. Prodi, M. T. Gandolfi in Handbook of Photochem istry, 3edrd edCRC Press, New York, 2006, pp. 601604.

[44] I. Carmichael, G. L. Hug, J. Phys. Chem. Ref. Data 1986, 15, 1250

[45] C. Reichardt, Solvents and solvent effects in organic chemistry, 3rd Ed., Wiley VCH, Weinheim, 2003. 